\title{
Ensino-aprendizagem de língua inglesa e uso de mídias sociais no Projeto Casas de Cultura no Campus: gamification e letramento crítico
}

\author{
Diogo Fagundes Barros ${ }^{1}$ \\ Sérgio Ifa ${ }^{1}$
}

\section{Resumo}

O objetivo do artigo é analisar como a perspectiva do Letramento Crítico (LC) juntamente com a gamificação das aulas impactam o desenvolvimento linguístico e na formação cidadã dos alunos de nivel Intermediário 1 de língua inglesa do Projeto Casas de Cultura no Campus (CCC) da Universidade Federal de Alagoas (Ufal). O foco teórico está nas discussões de Lewison, Flint e V an Sluys (2002) e Janks (2012, 2013) sobre a perspectiva do letramento crítico, no uso de mídias sociais na sala de aula como discutido por Nunan (1999) e Prensky (2001) e nas características da gamificação discutidas por Kapp (2012) e Sheldon (2011). Para dar conta do objetivo, a pesquisa qualitativa escolbida foi a pesquisa-ação (TRIPP, 2005). Os resultados revelam o efeito positivo no desenvolvimento linguístico dos alunos com o uso de elementos da gamificação e da perspectiva do LC. Resultados ainda revelam que o uso das midias sociais contribuin significativamente no processo de formação cidadã dos alunos.

Palavras-chave: Lingua inglesa. Letramento crítico.

Gamificaşão. Mídias sociais. Projeto de extensão

${ }^{1}$ Universidade Federal de Alagoas.

Revista Leitura v. 2, no 61 - Maceió - Jul./Dez. 2018 - ISSN 2317-9945

Ensino de línguas adicionais e formação de professores em cursos do Idiomas sem Fronteiras ou de extensão, p. 137-155 


\section{Introdução e objetivos}

A utilização de meios cibernéticos para o ensino-aprendizagem de línguas estrangeiras é um assunto muito debatido desde os anos 90, por exemplo, por Nunan (1999) e Hiltz (1995). Entretanto, foi apenas nos anos 2000 que ocorreu o "boom” tecnológico com a produção em massa e a popularização de computadores, tablets e smartphones, por exemplo. Este evento facilitou o acesso a meios tecnológicos de tal forma que quase todos possuem um aparelho tecnológico que lhes permite ter acesso a uma inesgotável fonte de informação, a internet. Prensky (2001) diz que os alunos atuais (do século XXI) não são iguais aos que aprendiam antigamente e que eles mudaram de tal forma que talvez não haja uma forma de voltar. Portanto, é de extrema importância que o docente seja letrado digitalmente, de modo que ele seja capaz de fazer uso de todas as funções dos meios disponibilizados em ambientes de ensino-aprendizagem.

Partimos da perspectiva que saber fazer uso dessas mídias, embora necessário, não é suficiente e acreditamos que o uso de uma perspectiva crítica como a do Letramento Crítico (JANKS, 2013; WOOD, SOARES \& WATSON, 2006; COSTA, 2012) seja extremamente necessário para o processo de ensino-aprendizagem, pois ela aproxima a língua à realidade do aluno ao trazer questões relevantes para a vida do mesmo, ao mesmo tempo que ajuda no desenvolvimento crítico do aluno ao mostrar múltiplas visões acerca dos tópicos abordados.

Este artigo enfoca dois semestres de um curso de inglês para alunos do nível intermediário em que atividades foram elaboradas cuidadosamente a partir das leituras de gamificação e da perspectiva do $\mathrm{LC}^{2}$. Além disso, o cumprimento das atividades acontecia com a ajuda das mídias sociais. O objetivo deste artigo é analisar os efeitos da imersão proporcionada pelas atividades no desenvolvimento da língua inglesa e também na formação cidadã desses aprendizes de inglês.

\footnotetext{
2 Projeto de pesquisa aprovado com o número 34095114.3.0000.5013. Todos os participantes envolvidos na
} pesquisa assinaram o termo de Consentimento Livre e Esclarecido (TCLE).

Revista Leitura v. 2, nº 61 - Maceió - Jul./Dez. 2018 - ISSN 2317-9945

Ensino de línguas adicionais e formação de professores em cursos do Idiomas sem Fronteiras ou de extensão, p. 137-155 


\section{Metodologia}

Para atingir nossos objetivos, escolhemos a pesquisa qualitativa chamada na modalidade pesquisa-ação seguindo as orientações de Tripp (2005, p. 433) que a define como: "toda tentativa continuada, sistemática e empiricamente fundamentada de aprimorar a prática". Tal metodologia requer que o pesquisador (o professor) esteja inserido no meio pesquisado (projeto de extensão) e que a população pesquisada (alunos de nível intermediário) possua uma participação ativa no processo.

Lewin (1946) descreve a pesquisa-ação como sendo um ciclo composto por: investigar uma prática, avaliar rigorosamente os resultados obtidos, planejar uma melhoria para a prática em questão, agir para implantar esta melhoria, monitorar e descrever os efeitos da ação e voltar a repetir o ciclo. Tripp $(2005$, p. 446) também propõe um ciclo que se assemelha ao proposto por Lewin, como apresentado abaixo na figura 1.

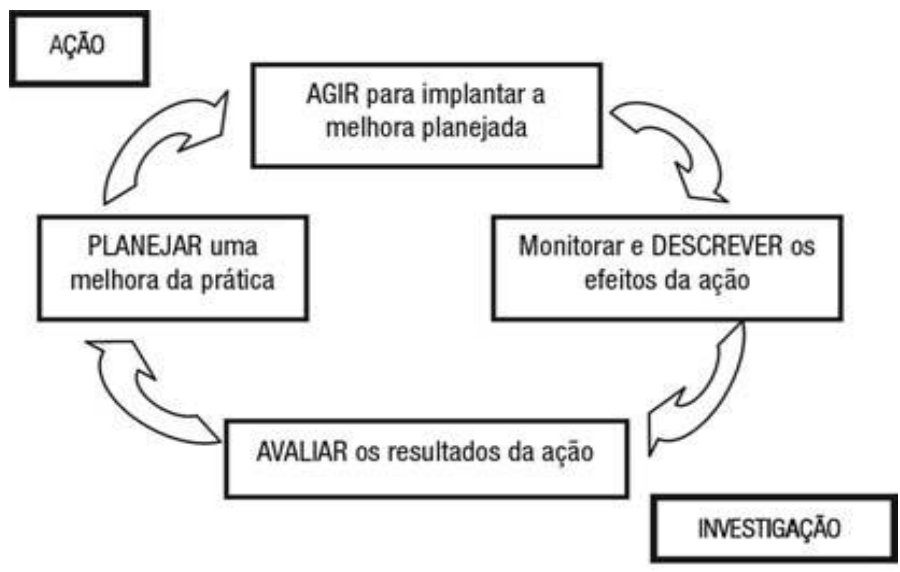

Figura 1: fases que compõem o ciclo básico da investigação-ação.

O intuito deste ciclo é fazer com que o pesquisador, preocupado ou incomodado com a aprendizagem dos alunos ou com a forma como ensina, esteja sempre buscando uma melhoria. O ciclo, portanto, pode ser repetido até termos um resultado satisfatório. Pela 
experiência com esse aporte teórico em turmas do projeto de extensão, o desafio lançado foi inicialmente trabalhar temas que fossem do interesse dos alunos ${ }^{3}$.

A investigação e coleta de dados aconteceu no Projeto Casas de Cultura no Campus ${ }^{4}$ (CCC) da Universidade Federal de Alagoas (Ufal). Foram ministradas aulas para duas turmas de nível intermediário 1, uma de junho de 2016 até novembro do mesmo ano, e outra de janeiro de 2017 até maio do mesmo ano. As aulas aconteciam duas vezes por semana e tinham duração de 100 minutos. Os participantes foram 40 alunos de vários cursos de graduação de uma universidade federal. Os dados coletados totalizaram 20 planos de aula, 75 atividades escritas e orais, dois questionários iniciais, sete apresentações finais, doze diários reflexivos acerca das aulas ministradas, seis gravações dos áudios das aulas, duas capturas de tela, sendo uma delas do Facebook e a outra do Whats App. Para este artigo, enfocamos a interpretação das produções orais e escritas de três alunos, são eles: aluno A, de 23 anos e graduando em Química - Licenciatura; aluna C, de 20 anos e graduanda em Direito; e aluna L, de 21 anos e graduanda em Psicologia.

Optamos por analisar quatro temas que trabalhamos: a guerra entre a cultura islâmica e a cultura ocidental (primeiro tema), o machismo na sociedade atual (segundo tema), a ascensão de discursos extremistas na atualidade (terceiro tema) e a representatividade de minorias em diversas mídias (quarto e último tema).

O objetivo da pesquisa foi transformado nas seguintes perguntas de pesquisa:

1) Qual é o efeito da imersão proporcionada pelas atividades gamificadas e embasadas no letramento crítico no desenvolvimento da língua inglesa dos alunos?

\footnotetext{
3 Tais temas foram selecionados após a aplicação de um questionário inicial cujo objetivo era o levantamento das necessidades e interesses dos alunos. Neste questionário, eles indicaram os temas que gostariam de trabalhar e/ou que estão mais próximos da realidade deles.

${ }^{4}$ O Projeto Casas de Cultura no Campus (CCC) é um projeto de extensão da Faculdade de Letras (Fale) que acontece no campus Maceió e promove tanto a formação docente para os futuros professores como oferece cursos de línguas para a comunidade acadêmica. São oferecidas aulas de língua inglesa, espanhola, francesa, Libras e português instrumental para os graduandos do campus. Os professores do CCC, chamados de professores em formação inicial (PFIs), são estudantes de Letras e cumprem algumas tarefas, a saber: ministram duas aulas semanais de 100 minutos cada para uma turma com até 30 alunos, participam de reuniões teórico-metodológicas semanalmente, pesquisam suas práticas, elaboram atividades e planos de aula, escrevem diários reflexivos, entre outras tarefas.
}

Revista Leitura v. 2, nº 61 - Maceió - Jul./Dez. 2018 - ISSN 2317-9945

Ensino de línguas adicionais e formação de professores em cursos do Idiomas sem Fronteiras ou de extensão, p. 137-155 
2) Qual é o efeito da imersão proporcionada pelas atividades gamificadas e embasadas no letramento crítico na formação cidadã dos alunos?

Quando Prensky (2001) afirma que a mentalidade dos atuais alunos (do século XXI) mudou extremamente, ele implicitamente levanta um questionamento: como os educadores podem fazer uso desta mudança para aprimorar a relação de ensino-aprendizagem entre professor e aluno? É sabido que os alunos estão cada vez mais conectados à tecnologia e que os professores devem buscar formas alternativas de ensino para podermos nos adaptar a esta realidade.

Tendo isso em mente, procuramos formas de usar duas das redes sociais mais utilizadas no Brasil: Facebook e Whats App para fins de ensino-aprendizagem. A primeira rede social foi utilizada para a realização de atividades escritas e envio de materiais para leitura. O Whats $A p p$ foi utilizado para pequenos debates tanto escritos quanto orais acerca de um tema apresentado em aula e para dar recados sobre tarefas e aulas.

\section{Gamificação e Letramento Crítico em prática}

Baseando-nos teoricamente em Letramento Crítico (LC), gamificação e uso das mídias sociais, tínhamos como objetivo o desenvolvimento das quatro macro habilidades comunicativas dos alunos em língua inglesa (compreensão oral e escrita e produção oral e escrita) ao trazer temas de interesse dos mesmos. $\mathrm{O}$ intuito desta união foi investigar como o uso destas perspectivas de ensino afeta o processo de desenvolvimento linguístico e a formação cidadã dos alunos.

É sabido que a motivação é aspecto fundamental do aprendizado do aluno, pois o aluno motivado tende a participar mais no processo de ensino-aprendizagem. Tendo isso em vista e também com o intuito de promover mais engajamento e participação por parte dos alunos, adotamos o conceito de gamificação apresentado por Kapp (2012), que a descreve como o uso de elementos de jogos para facilitar a compreensão e o aperfeiçoamento de trabalhos/tarefas nas aulas. Em outras palavras, a gamificação busca transformar o processo de ensino-aprendizagem em um jogo.

Revista Leitura v. 2, nº 61 - Maceió - Jul./Dez. 2018 - ISSN 2317-9945

Ensino de línguas adicionais e formação de professores em cursos do Idiomas sem Fronteiras ou de extensão, p. 137-155 
Ainda acerca dos aspectos imersivos e motivacionais da gamificação, nos deparamos com a seguinte pergunta: tendo em vista que a motivação é um dos principais elementos imersivos da gamificação, como nós poderíamos continuar mantendo os alunos motivados e consequentemente engajados? A resposta para tal pergunta foi encontrada em Keller (1987), que explica que a motivação surge quando há atenção, relevância, confiança/convicção e satisfação $\left(\mathrm{ARCS}^{5}\right)$. De acordo com o autor, o modelo ARCS deve ser aplicado para incontáveis formas de aprendizado e para jogos também.

Diante disso criamos um universo gamificado, onde os alunos seriam embaixadores da Terra, que deveriam visitar inúmeros planetas diferentes com o intuito de solucionar os problemas lá encontrados. Todos os problemas em questão foram baseados em questões que estão em evidência na atualidade, como a criação de leis que dividissem a população na qual uma minoria estaria reivindicando seus direitos, envolta em escândalos políticos e choques culturais. Estes temas foram utilizados sempre com o intuito de levantar múltiplos pontos de vista acerca de um mesmo tema e de exigir do aluno um pensamento mais crítico acerca dos problemas encontrados.

O início do processo imersivo propiciado por este novo universo fica claro na atividade inicial proposta na segunda turma, na qual os alunos deveriam criar uma personagem, que passaria a ser a identidade deles naquele curso, e deveriam se apresentar no grupo criado no Facebook como seus respectivos personagens. Abaixo, segue uma captura de tela da atividade em questão.

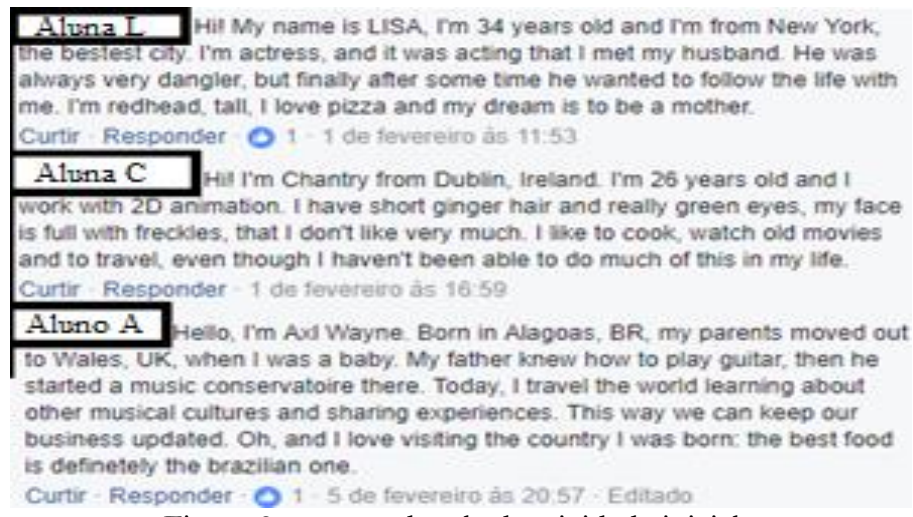

Figura 2: captura de tela da atividade inicial.

${ }^{5}$ Do original: “Attention, Relevance, Confidence and Satisfaction” (KELLER, 1987, p. 2-10).

Revista Leitura v. 2, nº 61 - Maceió - Jul./Dez. 2018 - ISSN 2317-9945

Ensino de línguas adicionais e formação de professores em cursos do Idiomas sem Fronteiras ou de extensão, p. 137-155 
Gostaríamos de destacar o fato de que os alunos criaram histórias que iam além do básico "nome, idade e local de nascimento". Alguns alunos, como $L$ e $A$, elaboraram uma família para seus personagens (marido para $L$ e pais para $A$ ), enquanto $C$ optou por fazer uma descrição mais detalhada da aparência de sua personagem. Ambos casos fizeram com que eles tivessem que procurar mais conhecimento e usassem mais recursos linguísticos para se expressar e contar suas respectivas histórias.

Com nosso "universo" criado e o processo imersivo iniciado, entregamos um questionário inicial aos alunos para que eles, dentre outras coisas, elencassem alguns temas ou assuntos de sua preferência que gostariam de ver em sala. Por conta da limitação de espaço para este artigo, escolhemos dentre os vários trabalhados nos cursos, para descrição e interpretação dos dados, apenas 4 temas $^{6}$. O tema 1 foi a guerra entre a cultura islâmica e a cultura ocidental (representado por duas culturas alienígenas que entraram em guerra, na qual uma possui aspectos semelhantes aos da cultura ocidental e a outra aspectos da cultura islâmica); o tema 2 foi sobre o machismo na sociedade atual (representado por uma sociedade alienígena onde o governo estava retirando os direitos das mulheres desta espécie); o tema 3 foi sobre a ascensão de discursos extremistas na atualidade (representado por um planeta onde representantes oficiais com ideias radicais estavam assumindo cargos de poder); e o tema 4 lidou com a representatividade de minorias em diversas mídias (representada por uma raça alienígena que foi completamente removida dos meios de comunicação, ou relegada a pequenas aparições).

Para a elaboração dos trabalhos com os temas, fizemos uso da perspectiva do Letramento Crítico (LC) que, de acordo com Wood, Soares e Watson (2006, p. 56), evoluiu a partir dos estudos realizados na Escola de Frankfurt e se baseiam na ideia de que "humanos podem mudar a sociedade através de palavras e ações"7.

Outra definição de LC é proposta por Costa (2012, p. 922) que a define como sendo uma perspectiva que vai além do trabalho em sala porque não só afeta como também modifica a própria relação de ensino-aprendizagem da língua estrangeira.

${ }^{6}$ Os 4 temas foram trabalhados em sala de aula nesta sequência apresentada.

7 Do Original: "humans can change society through words and actions". Tradução nossa.

Revista Leitura v. 2, nº 61 - Maceió - Jul./Dez. 2018 - ISSN 2317-9945

Ensino de línguas adicionais e formação de professores em cursos do Idiomas sem Fronteiras ou de extensão, p. 137-155 
Lewison, Flint e Van Sluys (2002, p. 382) sintetizam LC em quatro dimensões: “(1) romper com o lugar comum, (2) interrogar múltiplos pontos de vista, (3) focar-se em problemas sociopolíticos, e (4) tomar ação e promover justiça social"8.

Dentre as inúmeras definições de LC, optamos por adotar a proposta por Hillary Janks (2013) porque:

Essencialmente, letramento crítico é sobre permitir que os jovens leiam ambos o mundo e a palavra em relação a poder, identidade, diferença, e acesso a conhecimento, habilidades, ferramentas e recursos. Letramento Crítico também é escrever e reescrever o mundo: é desenhar e redesenhar ${ }^{9}$ (JANKS, 2013, p. 227).

Para a autora, a perspectiva do LC é aquela que questiona e procura promover a desconstrução das práticas que se focam em manter os privilégios de um determinado grupo em relação a outros, ou ainda das práticas que ignoram questões como diversidade e acesso. Janks (2013) também acredita na importância de se trabalhar os quatro pilares básicos e essenciais para promover a criticidade. São eles: poder (o quão poderosa e abrangente é uma determinada prática), acesso (quem tem acesso a tal prática), diversidade (quais grupos são afetados por esta prática) e construção/reconstrução ([re]construir uma determinada prática) ${ }^{10}$. Janks (2013) salienta que os quatro pilares são interdependentes e necessitam ser trabalhados a fim de buscar uma expansão da conscientização de como discursos e textos posicionam autores e interlocutores

\section{Resultados e discussões}

Nesta seção, apresentamos os resultados e a nossa interpretação sobre o trabalho realizado para verificar quais foram os efeitos ou impactos da imersão das atividades no desenvolvimento da língua inglesa e na formação cidadã dos alunos de nível intermediário do projeto. Iniciamos com os impactos identificados no desenvolvimento da língua inglesa.

8 Do Original: "(1) disrupting the commonplace, (2) interrogating multiple viewpoints, (3) focusing on sociopolitical issues, and (4) taking action and promoting social justice".

${ }^{9}$ Do Original: "Essentially, critical literacy is about enabling young people to read both the word and the world in relation to power, identity, difference and access to knowledge, skills, tools and resources. It is also about writing and rewriting the world: it is about design and re-design".

${ }^{10}$ Do original: Power, Access, Diversity and Design/Re-design.

Revista Leitura v. 2, nº 61 - Maceió - Jul./Dez. 2018 - ISSN 2317-9945

Ensino de línguas adicionais e formação de professores em cursos do Idiomas sem Fronteiras ou de extensão, p. 137-155 
Para interpretar os impactos do desenvolvimento da língua inglesa dos alunos, utilizamos como parâmetro a forma como as ideias por eles levantadas foram elaboradas, defendidas e contestadas; os argumentos que eles disseram; e o uso da língua inglesa nas produções orais e escritas. Neste artigo, optamos por interpretar as produções da aluna L. Foram quatro textos escritos da aluna L e um diálogo que ele teve com o aluno A.

\section{Aluna L Hil My name is LISA, I'm 34 years old and I'm from New York, the bestest city. I'm actress, and it was acting that I met my husband. He was always very dangler, but finally after some time he wanted to follow the life with me. I'm redhead, tall, I love pizza and my dream is to be a mother.}

Figura 3: texto referente à atividade inicial.

Em seu primeiro texto (figura 3), a aluna L revelou um texto simples e com problemas de coesão e coerência, mas possível de compreender quem é a personagem: uma mulher de 34 anos, casada e moradora de Nova Iorque.

Ao comparar o texto acima com o próximo texto escrito sobre "a guerra entre a cultura islâmica e a cultura ocidental", podemos perceber que tratar de culturas exigiu da aluna orações complexas e vocabulário específico. Apesar de apresentar alguns deslizes linguísticos ${ }^{11}$ acrossing, that caracteristics e feature set, ela conseguiu se expressar.

A aluna L, em seu texto sobre o tema 1 (figura 4), explica que diariamente julgamos os outros baseados em estereótipos que foram construídos em nós desde quando nascemos. Cita, como exemplo, o estereótipo negativo que temos sobre os muçulmanos.

11 Salientamos que as produções escritas da aluna $\mathrm{L}$ apresentadas aqui foram as suas primeiras versões das atividades solicitadas. Quisemos mostrar o seu desenvolvimento no uso da língua em diversas situações com diferentes temas. Entendemos que a exposição a diferentes temas e situações revela uma característica do curso de inglês do projeto do qual fazemos parte. Salientamos também que os deslizes gramaticais e as inadequações de vocabulário foram trabalhadas posteriormente. Priorizamos, nesse momento, a valorização do conteúdo do que queriam dizer sobre o uso correto da língua desde seu primeiro rascunho.

Revista Leitura v. 2, nº 61 - Maceió - Jul./Dez. 2018 - ISSN 2317-9945

Ensino de línguas adicionais e formação de professores em cursos do Idiomas sem Fronteiras ou de extensão, p. 137-155 
Aluna L It is very commom to see people acrossing the street or changing his/her seat on the bus because of someone with a specific characteristic or a feature set. It happens because since they were born, they learn that people with that characteristics are bad and will make wrong and bad things.

Aluna L One example of stereotype related to this is that muslim people are terrorists that want to destroy the USA. Other example also related to this is every woman who wears Hijab, the Islam veil, is a terrorist or agrees with it.

Figura 4: atividade no Facebook sobre o tema 1.

Além do texto escrito por L, a aluna também participou nas atividades em sala de aula e revelou um bom domínio do tema. Em um determinado momento da aula, ao responder ao alienígena, ela diz: "The situation we live in our planet is similar with the one on yours. We have two completely different cultures that fight to see which one is the "correct"' 12 . Reconhecemos não apenas o bom argumento para persuadir o(s) interlocutor(es) mas também o uso da língua inglesa como sinal de desenvolvimento linguístico.

Ao longo dos cursos organizamos diversas discussões e debates entre os alunos para que os mesmos pudessem expressar seus pontos de vista. Optamos por transcrever o diálogo entre a aluna L e o aluno A durante uma das aulas do tema 2, machismo na sociedade atual, quando os mesmos foram questionados acerca de como as mulheres são tratadas no planeta Terra.

Aluna L: "Women have some rights, but I think we need more rights for protection because lot of bad things happen with women"13.

Aluno A: "What do you mean?"14.

Aluna L: "If women use short clothes she will be 'puta' or 'asking to be raped'. I think we that should change"15.

Aluno A: "Then don't use short clothes. The rape only happen on dangerous place, if she is on good place that don't happen"16.

\footnotetext{
12 "A situação que vivemos em nosso planeta é parecida com a do seu planeta, temos duas culturas completamente diferentes que se confrontam para ver qual é a 'certa"'.

13 Aluna L: "Mulheres têm alguns direitos, mas acho que nós precisamos de mais direitos de proteção, pois várias coisas ruins acontecem com mulheres".

14 Aluno A: "O que você quer dizer?".

15 Aluna L: "Se uma mulher usa roupas curtas ela será uma 'puta' ou estará 'pedindo para ser estuprada'. Eu acho que isso deveria mudar".

16 Aluno A: "Então não use roupas curtas. O estupro só acontece em locais perigosos, se ela estiver em um local bom isso não irá acontecer".
}

Revista Leitura v. 2, nº 61 - Maceió - Jul./Dez. 2018 - ISSN 2317-9945

Ensino de línguas adicionais e formação de professores em cursos do Idiomas sem Fronteiras ou de extensão, p. 137-155 
Aluna L: "But I want to use short clothes and people should not care about this. People should respect me, not think that I am 'asking to be raped'. We should teach men to respect women, not teach women to use 'good clothes"'17.

O aluno A acaba concordando com a aluna L. Os colegas de turma aplaudem porque o argumento de L foi muito persuasivo.

Ao interpretar a conversa, realçamos o propósito comunicativo das trocas e a valorização do que estava sendo dito. As trocas favoreceram a interação, a negociação de significados, a sensação de que estavam sendo compreendidos porque conversavam sobre um assunto que era de interesse da maioria. Salientamos que os erros gramaticais identificados, tais como: a falta da conjugação de alguns verbos na terceira pessoa do singular, o fato de ambos terem usado a palavra use ao invés de wear para o uso de roupas e a ausência de alguns artigos indefinidos ("a") foram trabalhados em momentos posteriores. Apesar dos erros, ambos alunos conseguiram expressar suas ideias e foram compreendidos pelo restante da sala também.

Com o decorrer do curso os alunos se demonstraram mais tranquilos em expor suas opiniões e detalhes sobre suas vidas. Um exemplo disso foi o fato de a aluna L expor sua opinião política (algo que os alunos não se sentiam confortáveis em fazer no início do curso por receio de gerar um clima negativo com seus colegas de classe). O texto abaixo foi referente a uma atividade do tema 3 (a ascensão de discursos extremistas na atualidade), em que a aluna L definiu o que entende por discursos extremistas e quem seriam as vítimas de tais discursos:

\footnotetext{
17 Aluna L: "Mas eu quero usar roupas curtas e as pessoas não deveriam se importar com isso. Elas deveriam me respeitar, não pensar que estou pedindo 'pra ser estuprada'. Nós deveríamos ensinar homens a respeitar as mulheres, não ensinar as mulheres a usarem 'roupas boas"'.
}

Revista Leitura v. 2, nº 61 - Maceió - Jul./Dez. 2018 - ISSN 2317-9945

Ensino de línguas adicionais e formação de professores em cursos do Idiomas sem Fronteiras ou de extensão, p. 137-155 


\begin{abstract}
Aluna L Nowadays, the most extremist speech to me comes from the "right speech". Since I consider myself, my actions and ideas from the left side, speeches from Trump and Bolsonaro sounds extremes to me. To fight against this kind of speech, which is racist, sexist, homophobic, anti human right, etc. I believe in education and change our acts daily.

Today, some speeches sounds pretty similar. They(right people) have been showing more and more how they are against LGBTQ+ community, women's rights, social, racial and gender equality, etc. To me it is very extreme when you consider some lifes more important than others, and that is why I do beleive they are extremist.
\end{abstract}

Figura 5: atividade escrita da aluna L sobre o tema $3^{18}$.

Percebemos que a aluna L, em seu texto (figura 5), afirma que os discursos extremistas são realizados pelos grupos que se enquadram nas ideologias da direita porque valorizam algumas classes em detrimento das minorias. Na visão de L, algumas vidas não deveriam valer mais do que outras.

O texto de L, na figura 6, a seguir, é referente ao último tema: a representatividade de minorias em diversas mídias. A atividade solicitava aos alunos que respondessem aos colegas alienígenas, seres de outro planeta, sobre a presença de um casal homoafetivo em um desenho infantil. Qual opinião e reação dos terráqueos diante de tal cena? Abaixo, a resposta da aluna L:

\footnotetext{
18 Texto escrito na figura 5:

"Hoje em dia o discurso mais extremista vem do discurso da direita. Como eu me considero, considero minhas ações e ideias como sendo de esquerda, discursos de Trump e Bolsonaro me parecem extremos. Para combater esse tipo de discurso, o qual é racista, sexista, homofóbico, contra os direitos humanos, etc. eu acredito em educação e na mudança de nossas ações diárias.

Hoje, alguns discursos aparentam ser similares. Eles (pessoas de direita) têm mostrado mais e mais o quão contrários à comunidade LGBTQ+, direitos das mulheres e equidade social, racial e de gênero eles são. Para mim considerar algumas vidas mais importantes do que outras é algo extremo, e é por isso que eu acredito que eles são extremistas".
}

Revista Leitura v. 2, nº 61 - Maceió - Jul./Dez. 2018 - ISSN 2317-9945

Ensino de línguas adicionais e formação de professores em cursos do Idiomas sem Fronteiras ou de extensão, p. 137-155 

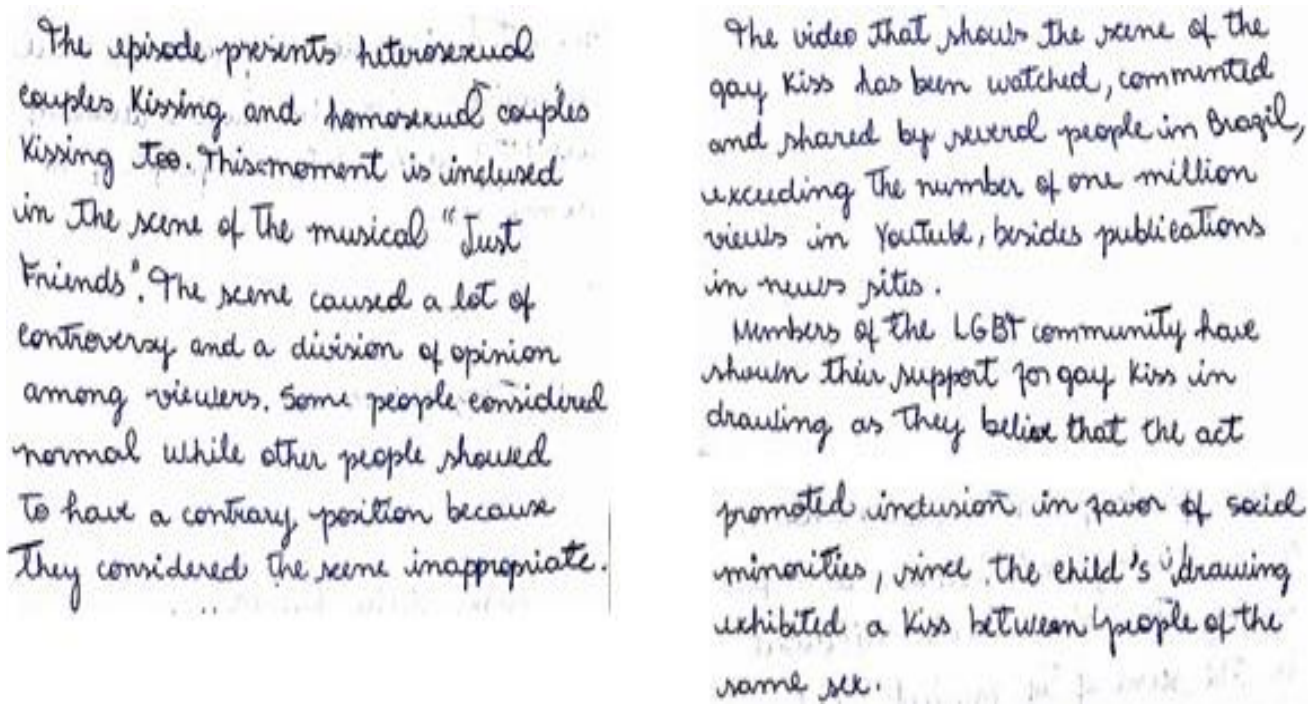

Figura 6: atividade escrita da Aluna L sobre o tema $4^{19}$.

Identificamos que L, em seu texto (figura 6), apresenta ideia concisa e argumento bem elaborado e faz uso correto de conectores (and, while e since) para deixar claro seu posicionamento. Salientamos que as atividades foram muito significativas para todos os participantes porque o desenvolvimento na língua inglesa, a partir da exposição à língua via habilidades de leitura e escuta, para produção na escrita e oralidade é concreto e visível, ajudando os alunos a se tornarem mais confiantes ao usarem a língua em contextos reais, pois oferecemos espaços para expressão e negociação de significados.

Não apenas os alunos demostraram que se desenvolveram em língua inglesa por meio da capacidade de expressão como conseguimos verificar que eles foram expostos a situações que contribuíram na formação cidadã, assunto que será discutido a seguir, quando interpretarmos os argumentos que os alunos usaram para demonstrar o quão críticos se revelaram.

\footnotetext{
19 Texto escrito na figura 6:

"O episódio mostra casais heterossexuais e homossexuais se beijando. Esse momento acontece na cena do musical Just Friends. A cena causou muita controvérsia e uma divisão de opiniões dentre os espectadores. Alguns consideram como algo normal enquanto outros apresentaram opiniões contrárias por considerarem a cena inapropriada.

O vídeo que mostra a cena do beijo gay foi assistido, comentado e compartilhado por diversas pessoas no Brasil, excedendo o número de um milhão de visualizações no YouTube, além de publicações em sites de notícia.

Membros da comunidade LGBT mostraram seu suporte ao beijo gay no desenho por acreditarem que o ato promoveu inclusão a favor das minorias, tendo em vista que o desenho infantil apresentou um beijo entre pessoas do mesmo sexo".
}

Revista Leitura v. 2, nº 61 - Maceió - Jul./Dez. 2018 - ISSN 2317-9945

Ensino de línguas adicionais e formação de professores em cursos do Idiomas sem Fronteiras ou de extensão, p. 137-155 
Nesta segunda parte da seção, queremos salientar que para identificar se os argumentos usados pelos alunos $A, C$ e $L$, em suas produções textuais, contemplavam aspectos baseados no letramento crítico, elaboramos quatro critérios que deveriam ser contemplados para indicar posicionamento crítico. São eles: (1) quem afeta ${ }^{20}$ - interessava-nos saber se o argumento do aluno contemplava os grupos que eram afetados pelo ponto de vista dos textos que estavam sendo trabalhados; (2) por que afeta ${ }^{21}$ - interessava-nos saber se o aluno mencionava o(s) motivo(s) pelo(s) qual(is) os grupos eram afetados; (3) como afeta - interessava-nos saber se o argumento do aluno explicitava a forma como esses grupos eram afetados; e (4) reconhecer outras visões - interessava-nos saber se o aluno conseguia contemplar não apenas o seu ponto de vista, mas também, pelo menos, dois outros pontos de vista sobre o tema trabalhado. Enfatizamos a necessidade de ter mais que dois pontos de vista sobre cada tema que trabalhamos para evitar a tradicional visão binária de como enxergamos o mundo ou as situações: preto ou branco, certo ou errado, por exemplo. O gráfico abaixo sintetiza quais alunos revelaram quais critérios.

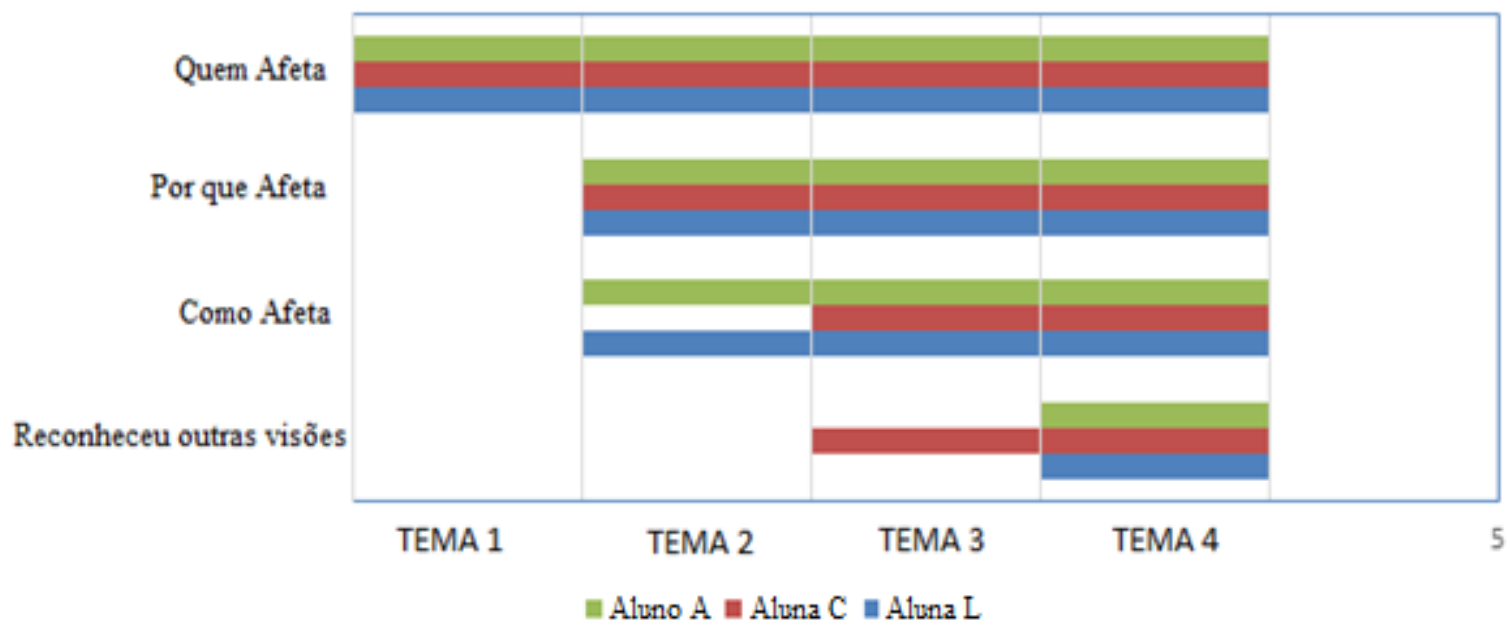

Figura 7: foco dos argumentos utilizados pelos alunos durante as aulas temáticas.

${ }^{20}$ A expressão "quem afeta" pode ser substituída por "quem sofre os impactos positivos ou negativos" como resultado do ponto de vista discutido no texto.

21 Ao mencionar "por que afeta", queremos enfocar se tanto as razões pelas quais determinado grupo é negligenciado quanto as consequências dessa negligência são mencionadas.

Revista Leitura v. 2, nº 61 - Maceió - Jul./Dez. 2018 - ISSN 2317-9945

Ensino de línguas adicionais e formação de professores em cursos do Idiomas sem Fronteiras ou de extensão, p. 137-155 
Os três alunos foram capazes de identificar e reconhecer as pessoas que poderiam ser $\operatorname{afetadas}^{22}$ ou prejudicadas pelos pontos de vista propostos nos quatro temas. Exemplificamos alguns argumentos:

"Ambos os lados [ambas culturas ocidental e islâmica] eram vítimas de estereótipos culturais levantados pela mídia de seu próprio lado" (Aluno A sobre o confronto entre a cultura islâmica e a cultura ocidental, tema 1);

"A sociedade como um todo sofre com isso, pois mulheres sofrem por serem vítimas diretas do machismo e homens por acabarem com uma visão extremamente preconceituosa e fechada da realidade" (Aluna C sobre machismo, tema 2);

"Esses discursos [extremistas] são contra a comunidade LGBTQ+, os direitos das mulheres e contra as igualdades social, racial e de gênero (Aluna L sobre a ascensão de discursos extremistas na atualidade, tema 3);

"Ainda que algumas pessoas se sintam incomodadas com a crescente representatividade de grupos de minorias, eles [os grupos] fazem parte da nossa realidade e negar representatividade para os mesmos apenas manteria o atual pensamento exclusivo no poder (Aluna L, sobre representatividade das minorias, tema 4).

O critério 2 "por que afeta" passou a ser contemplado pelos três alunos a partir do tema 2, o que nos alegrou, uma vez que, após o término do trabalho com o tema 1, mostramos aos alunos a necessidade de pensar e mencionar os quatro critérios para ampliar as perspectivas sobre o assunto. Exemplificamos alguns argumentos:

"As mulheres acabam perdendo a própria liberdade e ficam 'presas' a um padrão imposto pela sociedade" (Aluna C sobre machismo, tema 2);

"A partir do momento que permitimos um discurso extremista desses no poder estamos calando um negro/um gay/uma mulher, etc." (Aluno A sobre a ascensão de discursos extremistas na atualidade, tema 3;

"Uma simples cena de beijo causou essa discussão toda só por ter um casal homossexual" (Aluna L sobre a representatividade das minorias, tema 4).

Também no tema 2, os alunos A e L contemplaram em seus argumentos a forma como os grupos eram afetados pelo ponto de vista em questão:

\footnotetext{
22 Ao usar o termo afetadas, queremos dizer que são as pessoas que sofrem tanto os impactos positivos quanto os negativos.
}

Revista Leitura v. 2, nº 61 - Maceió - Jul./Dez. 2018 - ISSN 2317-9945

Ensino de línguas adicionais e formação de professores em cursos do Idiomas sem Fronteiras ou de extensão, p. 137-155 
"As mulheres são obrigadas a modificar sua forma de agir para se encaixarem nos padrões da sociedade, se não fizerem isso elas serão consideradas putas, ou irão 'desonrar a família delas"' (Aluna L sobre machismo, tema 2);

"Nós já estamos vendo os resultados disso com Trump querendo banir imigrantes e construir uma parede separando os EUA do México" (Aluno A sobre a ascensão de discursos extremistas na atualidade, tema 3);

"Existiram diversas pessoas querendo boicotar e censurar o desenho por causa desta cena, inclusive membros religiosos (pastores) fazendo vídeos contra o desenho. O mesmo aconteceu com uma propaganda há algum tempo pelo mesmo motivo" (Aluna L sobre a representatividade das minorias, tema 4).

Identificamos, no entanto, a dificuldade que os alunos tiveram em reconhecer outras visões nos temas 1 e 2. Optamos, portanto, por dar um foco maior nesse critério no tema 3 porque foi preocupante o fato de os alunos não terem conseguido reconhecer alguns pontos de vista acerca dos temas 1 e 2, uma vez que, nessa perspectiva do LC, a ampliação das visões para uma formação cidadã é um dos elementos fundamentais. No tema 3 (ascensão de discursos extremistas na atualidade), identificamos algum resultado com a aluna $\mathrm{C}$ conseguindo reconhecer outras visões: "Creio que tanto a esquerda quanto a direita possuem exemplos de discursos extremistas, pois já vi casos de feministas extremistas que não dialogam com um cara pelo fato dele ser homem". Já no tema 4 (representatividade das minorias) tivemos todos os quatro alunos sendo capazes de reconhecer múltiplos pontos de vista como aquele encontrado no texto escrito pela aluna L (figura 6).

\section{Considerações finais}

Ao preparar as aulas gamificadas e embasadas na perspectiva do LC percebemos o quão difícil e árdua seria esta tarefa, pois tínhamos que nos preocupar com diversos fatores como: tempo de preparo muito alto, dificuldades de encontrar material e ter que adaptá-lo ao contexto da gamificação. As mídias sociais (Facebook e WhatsApp) nos ajudaram muito no processo de gamificação, pois elas proporcionaram ambientes de rápida comunicação, extremamente útil para manter o interesse e a imersão dos alunos. As discussões e reflexões

Revista Leitura v. 2, nº 61 - Maceió - Jul./Dez. 2018 - ISSN 2317-9945

Ensino de línguas adicionais e formação de professores em cursos do Idiomas sem Fronteiras ou de extensão, p. 137-155 
realizadas nas mídias através de áudios gravados pelos alunos e por nós fizeram com que o ambiente de sala se tornasse mais propício para reflexões acerca dos temas trabalhados.

Após a coleta e intepretação dos dados, os resultados apontam que a imersão proporcionada pela gamificação, pelo menos no contexto das salas de aula, se revelou extremamente eficaz para o desenvolvimento linguístico dos alunos. Afirmamos isso tendo em vista que, como previamente apresentado, os alunos melhoraram sua capacidade argumentativa; isso ficou claro ao observarmos que os alunos passaram a usar estruturas gramaticais mais coerentes. Também acreditamos que a perspectiva do Letramento Crítico detalhada por Janks $(2012,2013)$ teve papel fundamental no processo, pois com ela os alunos tiveram a oportunidade de analisar diferentes perspectivas acerca de um mesmo tópico, de se colocarem no lugar de diversos grupos e de entender o efeito das forças de poder que atuam nos contextos estudados. Com esta oportunidade, os alunos deixaram de ser participantes passivos no processo de construção e reconstrução de sentidos e passaram a ocupar um papel mais crítico. Cremos que este aumento na criticidade do aluno fica claro quando analisamos o fato de que no início do curso os alunos apenas reconheciam quem era afetado pelas visões trabalhadas em sala e, com o passar do tempo, eles passaram a reconhecer mais aspectos acerca dos temas, como apresentado no gráfico (figura 7). Embora alguns tenham se sentido desconfortáveis em expor suas opiniões no início do curso, no final eles já estavam acostumados com as discussões de tal forma que a exposição de seus pontos de vista se tornou algo fácil e prazeroso para eles.

Por fim, passamos por desafios encontrados nesta pesquisa, como os já previamente mencionados por Sheldon (2011) acerca da gamificação e outros não sinalizados por ele: o desafio constante de bancar o "advogado do diabo", levantando e defendendo diversos pontos de vista, com o intuito de alimentar as discussões e promover uma criticidade maior por parte dos alunos; acreditamos que fomos capazes de fazê-los crescerem bastante como professores e cidadãos. Também fomos capazes de perceber o quão importante é o papel do professor pesquisador e a importância de estar sempre refletindo sobre as suas próprias práticas, pois sem isso a formação do professor fica estagnada: a formação deve ser contínua, pois há sempre espaços para novas aprendizagens.

Revista Leitura v. 2, nº 61 - Maceió - Jul./Dez. 2018 - ISSN 2317-9945

Ensino de línguas adicionais e formação de professores em cursos do Idiomas sem Fronteiras ou de extensão, p. 137-155 
Entendemos que LC não é uma questão de preto ou branco, certo ou errado, sim ou não, pois existem diversos discursos entre os extremos, discursos esses que muitas vezes são silenciados por forças opressoras. Assim cremos que todas as vezes que ficamos em um desses extremos estamos ajudando a silenciar outros discursos, e, ao nosso ver, o papel de um professor crítico é justamente agir de modo a impedir que seus alunos se mantenham em um desses extremos.

\section{Referências}

COSTA, E. Práticas de letramento crítico na formação de professores de línguas estrangeiras. RBLA, v. 12, $\mathrm{n}^{\circ}$ 4, 2012, p. 911-932.

HILTZ, S. The virtual classroom: learning without limits via computer networks. Norwood: Ablex Publishing Corporation, 1995.

JANKS, H. The importance of critical literacy. English teaching: practice and critique, v. 11, no 1,2012 , p. 150-163.

Critical literacy in teaching and research. Education Inquiry, Taylor \& Francis

Online, v. 4, nº 2, 2013, p. 225-242. Disponível em:

<https://doi.org/10.3402/edui.v4i2.22071>. Acesso em: 29 maio 2018.

KAPP, K. M. The gamification of learning and instruction: game-based methods and strategies for training and education: São Francisco: Pfeiffer, 2012.

KELLER, J. Development and use of the ARCS model of instructional design. Journal of Instructional Development, v. 10, no 3, 1987, p. 2-10. Disponível em: <https://doi.org/10.1007/BF02905780>. Acesso em: 29 maio 2018.

LEWIN, K. Action research and minority problems. Journal of Social Issues, v. 2, $\mathrm{n}^{\mathrm{o}} 4$, 1946, p. 34-36. Disponível em: <https://doi.org/10.1111/j.1540-4560.1946.tb02295.x>. Acesso em: 29 maio 2018.

LEWISON, M.; FLINT, A. S.; VAN SLUYS, K. Taking on critical literacy: the journey of newcomers and novices. Language Arts, v. 79, n 5, 2002, p. 382-392.

NUNAN, D. A foot in the world of ideas: graduate study through the internet. Language Learning \& Technology, v. 3, no 1, 1999, p. 43-60.

PRENSKY, M. Digital natives, digital immigrants - Part 1. On the Horizon, v. 9, nº 5, 2001, p. 1-6. Disponível em: <https://doi.org/10.1108/10748120110424816>. Acesso em: 29 maio 2018. 
SHELDON, L. The multiplayer classroom: designing coursework as a game. Boston: Cengage Learning PTR, 2011.

TRIPP, D. Pesquisa-ação: uma introdução metodológica. Educação e Pesquisa, v. 31, nº 3 , Set./Dez. 2005, p. 443-446.

WOOD, D.; SOARES, L.; WATSON, P. Empowering adolescents through critical literacy.

Middle School Journal, v. 37, nº 3, Jan. 2006, p. 55-59. Disponível em:

<https://doi.org/10.1080/00940771.2006.11461537>. Acesso em: 29 maio 2018.

\section{Abstract}

This research aims to analyze how the Critical Literacy (CL) perspective, alongside with the gamification of classes affect the linguistic development and the citizenship-oriented education of students from a university extension project. To do so, we make use of the immersion provided by the gamified activities, which were based on CL. We based our research on CL in Lewison, Flint and Van Sluys (2002) and Janks (2012, 2013), regarding the usage of social media in classrooms with Nunan (1999) and Prensky (2001) and regarding gamification with Kapp (2012) and Sheldon (2011). As research methodology we made use of the qualitative research called action-research (TRIPP, 2005). The results reveal the positive effect of the union between Gamification and CL regarding the students' linguistic development. This research also reveals that the English language teaching united with the usage of social media, supported by the gamification and the CL contributed in the process of citizenship-oriented education.

Keywords: English language. Critical literacy. Gamification. Social media. Community outreach project

Recebido em: 04/01/2018.

Aceito em: 11/07/2018.

Revista Leitura v. 2, nº 61 - Maceió - Jul./Dez. 2018 - ISSN 2317-9945

Ensino de línguas adicionais e formação de professores em cursos do Idiomas sem Fronteiras ou de extensão, p. 137-155 